\title{
The Importance of Inspiratory Maneuver for Benign Laryngeal Lesions
}

\author{
Marília Batista Costa ${ }^{1(0)}$ Taynara Oliveira Ledo ${ }^{1(0)}$ Mariana Delgado Fernandes ${ }^{1(0)}$ \\ Romualdo Suzano Louzeiro Tiago ${ }^{10}$ \\ ${ }^{1}$ Otorhinolaryngology Department, Hospital do Servidor Publico \\ Estadual de Sao Paulo, Sao Paulo, SP, Brazil \\ Int Arch Otorhinolaryngol 2020;24(4):e513-e517.

\begin{abstract}
Address for correspondence Marília Batista Costa, MD, Otorrinolaringologia, Hospital do Servidor Publico Estadual de São Paulo, Rua Pedro de Toledo, 1800, Vila Clementino, São Paulo, SP, 04029-000, Brazil (e-mail: marilia.batista.c@gmail.com).
\end{abstract}

\begin{abstract}
Introduction Inspiratory maneuver corresponds to a simple method used during videolaryngoscopy to increase characterizations of laryngeal findings, through the movement of the vocal fold cover and exposure of the ligament, facilitating its evaluation.

Objective To evaluate the increase in diagnosis of benign laryngeal lesions from the usage of inspiratory maneuvers during videolaryngoscopy in patients with or without vocal complaints.

Methods A cross-sectional study performed from March 1 to July 1, 2018, in the Laryngology sector of a tertiary hospital. The age of the patients varied from 18 to 60 years old. They were divided into two groups, symptomatic and asymptomatic vocals, and evaluated through videolaryngoscopy together with inspiratory maneuvers. The exams were recorded and later evaluated by three trained laryngologists who determined the laryngeal lesions before and after the inspiratory maneuver.

Results There were 60 patients in this sample, 41 of which were vocal symptomatic and 19 asymptomatic. The majority was female and the main complaint was about dysphonia. Before the inspiratory maneuver, the most observed lesions in both groups were chronic laryngitis, followed by vascular dysgenesis. After the inspiratory maneu-

Keywords

- diagnosis

- vocal cords

- laryngoscopy ver, sulcus vocalis was the most frequent additional finding.

Conclusion With the inspiratory maneuver, it was possible to increase the identification of structural lesions in the vocal fold, and the most frequent lesion in patients with or without vocal complaints was sulcus vocalis.
\end{abstract}

\section{Introduction}

One of the functions of the larynx is phonation. Voice is produced through the repeated movement of the vocal fold cover, producing a mucosal wave. The flexibility of the vocal fold is essential to promote the appropriate glottic vibration. ${ }^{1}$ However, the formation of a mucosal wave is modified by benign laryngeal lesions, its main examples being nodules, polyps, Reinke edema and minor structural alterations $(\mathrm{MSAs})^{2}$

received

December 17, 2018

accepted

July 18, 2019
DOI https://doi.org/

10.1055/s-0040-1702968. ISSN $1809-9777$.
A precise diagnosis is essential for therapeutic decisions as well as for the instructions to the patients about their illness and possible after effects. ${ }^{3,4}$ The diagnosis is made usually through endoscopic visualization, either by videolaryngoscopy with a rigid telescope or rhino-laryngo flexible fiberscope or videolaryngostroboscopy. ${ }^{5}$ It is also possible to do a suspension microlaryngoscopy, considered the best to diagnose benign laryngeal lesions. ${ }^{6}$

The inspiratory maneuver was initially described in 1957 by Powers et $\mathrm{al}^{7}$ from a radiological analysis of the larynx or

Copyright $\odot 2020$ by Thieme Revinter Publicações Ltda, Rio de Janeiro, Brazil

License terms

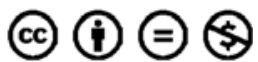


laryngography. Only in 2003 Kothe et $\mathrm{al}^{8}$ indicated its use to stimulate a precise way to classify Reinke edema. This maneuver corresponds to a simple method used during videolaryngoscopy. For this, which can be done through a rigid telescope or rhino-laryngo flexible fiberscope, the patient has to, after exhalation, inhale deeply and noisily. Thus, there is a better definition of the viscoelastic properties of the vocal folds and its cover alterations giving the suction of the free edge of the vocal fold toward the subglottis, with a good delimitation of the vocal ligament. ${ }^{8-10}$

The objective of the present study is to evaluate the increase in the diagnosis of benign laryngeal lesions using inspiratory maneuver during videolaryngoscopy in patients with or without vocal complaints.

\section{Methods}

Patients in the present cross-sectional study underwent a videolaryngoscopy at the ambulatory in the Laryngology sector of a tertiary hospital. They were analyzed from March 1 to July 1, 2018. The study has been evaluated and approved by the hospital's Ethical Committee in Research, under the CAAE number 85767318.4.0000.5463.

The research included patients between 18 and 60 years old who had adequately done videolaryngoscopy using inspiratory maneuver and filled out the written informed consent form.

The exclusion criteria established were: suspicion or confirmation of malign laryngeal lesion; previous laryngeal procedures, such as laryngeal microsurgery, cordectomy, partial or total laryngectomy; radiotherapy/chemotherapy in cervical regions; replacement of rigid telescope by rhinolaryngo flexible fiberscope resulting from intense nauseous reflex; difficulty or unsatisfactory inspiratory maneuver; laryngeal candidiasis compromising the vocal folds. Patients $>60$ years old were excluded due to the natural physiological aging and atrophy of the intrinsic laryngeal muscles of the age, therefore the vocal folds gain a curved aspect with a higher prominence in the vocal process. Related to it there is a reduction of mucous and saliva, restricting the vibrating capacity of the vocal folds.

There was a total of 201 patients, 141 of them were excluded. All reasons for exclusion are in -Table 1 .

Table 1 Causes and frequencies of patient exclusion

\begin{tabular}{|l|l|}
\hline Exclusion Reason & $\boldsymbol{n}(\%)$ \\
\hline Age $>60$ years old & $89(44.3 \%)$ \\
\hline Previous surgery & $26(12.9 \%)$ \\
\hline Intense nauseous reflex & $17(8.5 \%)$ \\
\hline Age $<18$ years old & $3(1.5 \%)$ \\
\hline Unsatisfactory inspiratory maneuver & $3(1.5 \%)$ \\
\hline Previous radiotherapy or chemotherapy & $2(1 \%)$ \\
\hline Laryngeal candidiasis (vocal folds) & $1(0.5 \%)$ \\
\hline Total & $141(70.2 \%)$ \\
\hline
\end{tabular}

The present work was performed in two steps:

1. Data collection and videolaryngoscopy: a structured interview in which epidemiological data was gathered, such as age, gender, clinical complaints (dysphonia, cough, throat clearing, globus pharyngeus, dysphagia, pyrosis, pain, patients without voice complaints, but having to do admission exams to work as teachers).

The instruments used for videolaryngoscopy were: Ferrari light source (E 50S, Ferrari Medical, São Paulo, SP, Brazil); Olympus OTV-SC camera system (Olympus, Tokyo, Japan); Precision larynx rigid telescope (Precision $8 \mathrm{mmx} 70^{\circ}$, Richards Medical, São Paulo, SP, Brazil), $70^{\circ}$ angulation; MZ Medical external microphone system (MZ Medical Products, São Paulo, SP, Brazil); Sony TV monitor model PVM-2053MD (Sony Corporation, Tokyo, Japan). All videos were backed up in a database, using a MyGica video recorder (MyGica, Shenzhen, China).

Patients were asked to sit, with their tonguess out, wrapped in gauze and kept in this position by the assessor's fingers pressure. The rigid telescope was inserted toward the oropharynx, visualizing the larynx. Patients with gag reflex received topical anesthesia in the oropharynx with $10 \%$ lidocaine spray.

Initially, a full larynx anatomy evaluation was made, including documentation of the supraglottis (breathing area), subglottis and trachea region. Afterwards, there was a functional evaluation through sustained phonation of the /i/ vowel, resulting in the elevation of the larynx and anteriorization of the epiglottis, facilitating visualization of the laryngeal structures. In the end, the patients were asked to do the inspiratory maneuver, which is a long and noisy inhale after exhaling.

To compare, patients were divided into two groups according to their clinical vocal complaints: symptomatic or asymptomatic. In the first group, the symptoms were: hoarseness and vocal fatigue. Other complaints mentioned in both groups were: pyrosis, throat clearing, pain, dysphagia, globus pharyngeus and cough.

2. Video analyses: the videos were backed up in a database and afterwards watched by three experienced laryngologists separately. Videos were shown at normal speed, slow motion or paused, according to the necessity of the evaluator. These professionals determined the findings and a possible diagnosis in each video before and after the maneuver, to confirm if the inspiratory maneuver would contribute to the additional alterations or if it would alter the initial diagnosis. The evaluators were not aware of the identification of the patients or of their vocal symptoms.

The additional laryngeal alterations were: signs of chronic laryngitis (hyperemia and edema of vocal folds, interarytenoid edema and subglottic edema), vocal nodules, pseudocyst, polyps, epidermoid cyst, sulcus vocalis, laryngeal asymmetry, Reinke edema, leukoplakia, mucosal thickening, vascular dysgenesis, vocal cord paresis, contact ulcer, laryngocele, laryngeal candidiasis, as well as exams without abnormalities. The same patient can have more than one diagnosed lesion.

For the statistic analysis, the lesions were counted in each vocal fold. Typically bilateral lesions, such as vocal nodule and Reinke edema, and the suggestive findings of laryngitis posterior (hyperemia and edema of interarytenoid region) 
were evaluated as unique bodies. Lesions classified as "contralateral reaction" were not considered.

\section{Statistical Analysis}

The categorical variables were represented through relative and absolute frequency. The variable figure "\%," referring to inspiratory maneuver, was calculated as the increase of lesions referring to the initial evaluation, as the following formula suggests: ((new diagnosis - initial evaluation) $\div$ initial evaluation) $\times 100=\%$ (-Table 2). Diagnoses with "initial evaluation” equal to zero were indicated by “*” ( - Table 3 ).

\section{Results}

The sample was formed by 60 patients according to the inclusion criteria, where 41 were vocal symptomatic and 19 vocal asymptomatic. The age group varied from 18 to 60 years old, the average being $47.3 \pm 10.3$ years old, and the majority was female (85\%) in both groups.

The most frequent complaint was dysphonia (68.3\%), followed by pyrosis (18.3\%), pain and throat clearing ( $16.7 \%$ each). In the group with vocal symptoms: $100 \%$ showed dysphonia; $24.4 \%$ pain and pyrosis; $22 \%$ vocal fatigue and $19.5 \%$ throat clearing. Among the asymptomatic: throat clearing and globus pharyngeus (10.5\% each); choke and pyrosis (5.3\% each). Patients without voice complaints and

Table 2 Frequency (n) and increase in the diagnosis (\%) of laryngeal lesions, before and after the inspiratory maneuver, according to type of lesion in general

\begin{tabular}{|l|l|l|l|}
\hline & Without IM & With IM & $\%$ \\
\hline Sulcus Vocalis & 11 & 66 & 500 \\
\hline Chronic Laryngitis & 40 & 40 & 0 \\
\hline Vascular Dysgenesis & 30 & 30 & 0 \\
\hline Mucosal Thickening & 21 & 21 & 0 \\
\hline Vocal Fold Atrophy & 7 & 7 & 0 \\
\hline Pseudocyst & 5 & 5 & 0 \\
\hline Reinke Edema & 4 & 5 & 25 \\
\hline Vocal Nodules & 4 & 4 & 0 \\
\hline Normal Exam & 5 & 4 & -20 \\
\hline Epidermoid Cyst & 3 & 3 & 0 \\
\hline Vocal Polyps & 2 & 2 & 0 \\
\hline Leukoplakia & 1 & 1 & 0 \\
\hline Bilateral Laryngocele & 1 & 1 & 0 \\
\hline Contact Ulcer & 1 & 1 & 0 \\
\hline Vocal Cord Paresis & 1 & 1 & 0 \\
\hline $\begin{array}{l}\text { Laryngeal Candidiasis } \\
\text { (epiglottis) }\end{array}$ & 1 & 1 & 0 \\
\hline Laryngeal Asymmetry & 1 & 193 & 40 \\
\hline Total & Without IM & With IM & $\%$ \\
\hline Diagnostics & 138 & 193 \\
\hline
\end{tabular}

Abbreviation: IM, inspiratory maneuver. the need for admission exams to teach were $26.7 \%$ of the sample.

Before the inspiratory maneuvers, the most observed lesions in both groups were chronic laryngitis, vascular dysgenesis, mucosal thickening and sulcus vocalis (-Tables 3 and 4). Generally, inspiratory maneuvers had a $40 \%$ increase in the diagnosis and the most common finding was sulcus vocalis, with a $500 \%$ increase in the diagnosis. Another lesion benefited by inspiratory maneuvers was Reinke edema (one case in the vocal symptomatic group), which had not been visualized with the videolaryngoscopy, with a $25 \%$ increase in the diagnosis (-Table 2). The frequency of diagnosis in the many laryngeal lesions, before and after the inspiratory maneuvers, are presented in -Tables 2-3 to 4 .

\section{Discussion}

It was observed, in the present study, a predominance of female (85\%), similar to another study, which described $77.5 \%$ of women in its casuistry of 80 patients with benign lesions in their vocal folds. ${ }^{11}$ A probable explanation for this would be the fact that a higher rate of women go to the doctor, as well as a higher fundamental frequency and less hyaluronic acid, that could facilitate the advent of glottic lesions. $^{12}$

In the present study, the average age was 47.3 years old. Dailey et $\mathrm{al}^{13}$ report an average age of 43.5 years old among the 100 patients who underwent suspension microlaryngoscopy due to larynx benign lesions. Printza et al ${ }^{14}$

Table 3 Frequency ( $n$ ) and increase in the diagnosis (\%) of laryngeal lesions, before and after the inspiratory maneuver, according to type of lesion in vocal asymptomatic patients

\begin{tabular}{|l|l|l|l|}
\hline & Without IM & With IM & $\%$ \\
\hline Sulcus Vocalis & 4 & 23 & 475 \\
\hline Chronic Laryngitis & 13 & 13 & 0 \\
\hline Vascular Dysgenesis & 9 & 9 & 0 \\
\hline Normal Exam & 4 & 3 & -25 \\
\hline Mucosal Thickening & 1 & 1 & 0 \\
\hline Reinke Edema & 0 & 1 & $*$ \\
\hline Vocal Fold Atrophy & 1 & 1 & 0 \\
\hline Vocal Cord Paresis & 1 & 1 & 0 \\
\hline $\begin{array}{l}\text { Laryngeal Candidiasis } \\
\text { (epiglottis) }\end{array}$ & 1 & 1 & 0 \\
\hline Pseudocyst & 0 & & \\
\hline Vocal Nodules & 0 & 0 & 0 \\
\hline Epidermoid Cyst & 0 & 0 & 0 \\
\hline Vocal Polyps & 0 & 0 & 0 \\
\hline Leukoplakia & 0 & 0 & 0 \\
\hline Laryngeal Asymmetry & 0 & 0 & 0 \\
\hline Bilateral Laryngocele & 0 & 0 & 0 \\
\hline Contact Ulcer & 0 & 0 & 0 \\
\hline
\end{tabular}

Abbreviation: IM, inspiratory maneuver. 
Table 4 Frequency ( $\mathrm{n}$ ) and increase in the diagnosis (\%) of laryngeal lesions, before and after the inspiratory maneuver, according to type of lesion in vocal symptomatic patients

\begin{tabular}{|l|l|l|l|}
\hline & Without IM & With IM & $\%$ \\
\hline Sulcus Vocalis & 7 & 43 & 514 \\
\hline Chronic Laryngitis & 27 & 27 & 0 \\
\hline Vascular Dysgenesis & 21 & 21 & 0 \\
\hline Mucosal Thickening & 20 & 20 & 0 \\
\hline Vocal Fold Atrophy & 6 & 6 & 0 \\
\hline Pseudocyst & 5 & 5 & 0 \\
\hline Vocal Nodules & 4 & 4 & 0 \\
\hline Reinke Edema & 4 & 4 & 0 \\
\hline Epidermoid Cyst & 3 & 3 & 0 \\
\hline Vocal Polyps & 2 & 2 & 0 \\
\hline Leukoplakia & 1 & 1 & 0 \\
\hline Laryngeal Asymmetry & 1 & 1 & 0 \\
\hline Normal Exam & 1 & 1 & 0 \\
\hline Bilateral Laryngocele & 1 & 1 & 0 \\
\hline Contact Ulcer & 1 & 1 & 0 \\
\hline Vocal Cord Paresis & 0 & 0 & 0 \\
\hline $\begin{array}{l}\text { Laryngeal Candidiasis } \\
\text { (epiglottis) }\end{array}$ & 0 & 0 & 0 \\
\hline
\end{tabular}

Abbreviation: IM, inspiratory maneuver.

showed an average of 51.4 years old, among the 150 patients who underwent videolaryngostroboscopy due to benign laryngeal alterations.

In the present study, the inspiratory maneuver was important for the increase of diagnosis of sulcus vocalis in 500\% and in $25 \%$ of Reinke edema (-Table 2 ). A total of $20 \%$ of the patients with initially normal results had a sulcus vocalis diagnosis after the inspiratory maneuver (-Table 2 ). Studies on the usage of inspiratory maneuvers to evaluate increases in the diagnosis of the benign larynx were not found. In the present study, inspiratory maneuvers did not change the initial diagnosis, although it allowed a $40 \%$ increase of diagnosis of lesions (-Table 2 ). Some studies evaluated the use of videolaryngostroboscopy to evaluate the increase in diagnosis. Casiano et $\mathrm{al}^{15}$ performed a study with 292 patients and observed a $19 \%$ change in the initial diagnosis and $24 \%$ of additional findings. Printza et al ${ }^{14}$ evaluated 150 patients with laryngeal benign lesions and observed that videolaryngostroboscopy was important in the increase of diagnosis by $28.8 \%$. The diagnostic value of videolaryngostroboscopy varied considerably depending on the lesion, being significant to: sulcus vocalis, cyst, nodules, fibrosis of vocal folds, vocal atrophy and psychogenic dysphonia. ${ }^{14}$

The explanation for a better identification of sulcus vocalis with inspiratory maneuvers is due to the movement of the vocal fold cover and exposure of the ligament (intermediate and deep layer of the lamina propria) with inspiratory phonation, resulting in their partial adduction. This medialization of vocal folds allows a detailed visualization of the cover and the lamina propria, and consequently evaluates its impairment., ${ }^{4,16}$ Besides this, the partial glottic closure promotes a barrier to the inhaled air, reducing subglottic pressure and increasing the supraglottic one. ${ }^{10,17}$ This increase promotes a distension of the ventricle of Morgagni, of vestibular folds and of the pyriform sinus, allowing a broad visualization of the supraglottis and consequently of the vocal folds. $9,10,17$

Literature reports suggest that inspiratory maneuver provides a distinction between deep and superficial lesions in the vocal fold mucous in relation to the lamina propria, with a possible application when differentiating nodule and cyst. The first, because it is more superficial, is not in contact with the vocal ligament, since it is limited to the epithelium. The cyst is characterized for being adhered or semi-adhered to the vocal ligament. ${ }^{4,5,17}$ In the present study, there were no changes in the initial diagnosis among these alterations after the inspiratory maneuver.

Despite not being the objective of the present study, the literature suggests the benefit of inspiratory maneuver in the visualization of a suggestive malign sign. In these cases, there is a restriction in the supraglottis distension, which can be embedded by the tumor. ${ }^{5,8,9}$

In the present study, $\sim 1.5 \%$ of the exams were excluded because the inspiratory maneuvers were performed in an unsatisfactory manner, all of these because of an inability of the patient to maintain a forced inspiration which caused problems for evaluation. Nauseous reflex was present in 8.5\% of cases; however, this is associated to the method of evaluation through the use of a rigid telescope, and not a result of the maneuver itself ( - Table 1 ). Casiano et al $^{15}$ commented that $34 \%$ of videolaryngostroboscopy exams were performed in an unsatisfactory manner. The motives given were: incapacity to maintain a stable fundamental frequency, reduced phonation time, deficient visualization as a result of large quantity of secretion, accentuated constriction of upper glottis or extensive lesions, noncollaborative patients. ${ }^{15}$

The present study showed a very high prevalence of sulcus vocalis, even in asymptomatic patients. Moraes et al ${ }^{18}$ submitted 147 patients to the suspension microlaryngoscopy and obtained a prevalence of MSAs in patients without vocal complaints of $21.1 \%$. Sulcus vocalis was present in $16.3 \%,{ }^{18}$ a lower prevalence when compared with microscopic assessment that obtained a prevalence of up to between 36 and $39 \%{ }^{19,20}$ This demonstrates that the presence of MSA is not necessarily related to dysphonia.

\section{Conclusion}

In the present study, the inspiratory maneuver provided an important increase in the diagnosis of sulcus vocalis. We recommend the use of this maneuver, even in asymptomatic patients, with the aim of early diagnosis of laryngeal alterations and, with this, prevent the development of secondary lesions.

\section{Conflict of Interests}

The authors have no conflict of interests to declare. 


\section{References}

1 Noordzij JP, Ossoff RH. Anatomy and physiology of the larynx. Otolaryngol Clin North Am 2006;39(01):1-10

2 Naunheim MR, Carroll TL. Benign vocal fold lesions: update on nomenclature, cause, diagnosis, and treatment. Curr Opin Otolaryngol Head Neck Surg 2017;25(06):453-458

3 Sulica L, Behrman A, Roark R. The inspiratory maneuver: a simple method to assess the superficial lamina propria during endoscopy. J Voice 2005;19(03):481-484

4 Poels PJP, de Jong FICRS, Schutte HK. Consistency of the preoperative and intraoperative diagnosis of benign vocal fold lesions. J Voice 2003;17(03):425-433

5 Rajput SD, Poriya MJ. Stroboscopy: an evolving tool for voice analysis in vocal cord pathologies. Int J Otorhinolaryngol Head Neck Surg 2017;3(04):927-931

6 Neto JAM, Pinna BR, Neto JC, de Sá Pedroso JE. Comparison between telelaryngoscopy and suspension laryngoscopy in the diagnosis of benign vocal fold lesions. Rev Bras Otorrinolaringol (Engl Ed) 2008;74(06):869-875

7 Powers WE, McGee HH Jr, Seaman WB. Contrast examination of the larynx and pharynx. Radiology 1957;68(02):169-178

8 Kothe C, Schade G, Fleischer S, Hess M. Forced inspiration: a laryngoscopy-based maneuver to assess the size of Reinke's edema. Laryngoscope 2003;113(04):741-742

9 Lehmann QH. Reverse phonation: a new maneuver for examining the larynx. Radiology 1965;84:215-222

10 Finger LS, Cielo CA. Reverse phonation-physiologic and clinical aspects of this speech voice therapy modality. Rev Bras Otorrinolaringol (Engl Ed) 2007;73(02):271-277
11 Colton RH, Woo P, Brewer DW, Griffin B, Casper J. Stroboscopic signs associated with benign lesions of the vocal folds. J Voice 1995;9(03):312-325

12 Butler JE, Hammond TH, Gray SD. Gender-related differences of hyaluronic acid distribution in the human vocal fold. Laryngoscope 2001;111(05):907-911

13 Dailey SH, Spanou K, Zeitels SM. The evaluation of benign glottic lesions: rigid telescopic stroboscopy versus suspension microlaryngoscopy. J Voice 2007;21(01):112-118

14 Printza A, Triaridis S, Themelis C, Constantinidis J. Stroboscopy for benign laryngeal pathology in evidence based health care. Hippokratia 2012;16(04):324-328

15 Casiano RR, Zaveri V, Lundy DS. Efficacy of videostroboscopy in the diagnosis of voice disorders. Otolaryngol Head Neck Surg 1992;107(01):95-100

16 Kelly CL, Fisher KV. Stroboscopic and acoustic measures of inspiratory phonation. J Voice 1999;13(03):389-402

17 Barata LF, Madazio G, Behau M, do Brasil O. Vocal and laryngeal analyses in diagnostic hypotheses of nodules and cysts. Rev Soc Bras Fonoaudiol 2010;15(03):349-354

18 Moraes BT, De Biase NG. Prevalence of Minor Larynx Structural Alterations: Influence on the Concept of a Normal Vocal Fold. Otolaryngol Head Neck Surg 2019;160(02):295-301

19 Hsiung MW, Woo P, Wang HW, Su WY. A clinical classification and histopathological study of sulcus vocalis. Eur Arch Otorhinolaryngol 2000;257(08):466-468

20 Sunter AV, Yigit O, Huq GE, Alkan Z, Kocak I, Buyuk Y. Histopathological characteristics of sulcus vocalis. Otolaryngol Head Neck Surg 2011;145(02):264-269 